\title{
The role of the hairy gene during Drosophila morphogenesis: stripes in imaginal discs
}

\author{
Sean B. Carroll and Jill S. Whyte \\ Laboratory of Molecular Biology, University of Wisconsin-Madison, Madison, Wisconsin 53706 USA
}

\begin{abstract}
The Drosophila pair-rule embryonic segmentation gene hairy is also required later in development to suppress the formation of certain adult sensory structures. Striking patterns of nuclear hairy protein distribution emerge during larval and pupal imaginal disc morphogenesis. hairy is expressed transiently in the cells just anterior to the morphogenetic furrow as it passes across the eye disc and in stripes along the proximo-distal axis of the leg discs and the developing veins of the wing disc. hairy expression is correlated with disc cell-cycle changes and is excluded from the sensory neurons that differentiate near or among the rows of hairy-expressing cells. It is likely that hairy regulates genes affecting neuronal determination, such as achaete, and is regulated by genes that specify anteroposterior polarity within imaginal discs.
\end{abstract}

[Key Words: Eye development; hairy; imaginal disc; morphogenesis; Drosophila]

Received February 7, 1989; revised version accepted April 3, 1989.

Through systematic screens for mutations in loci that visibly perturb the organization of the Drosophila embryo, geneticists have been able to identify and categorize several sets of genes that control fundamental aspects of embryonic pattern formation. Much emphasis has been placed on the characterization of genes controlling segment formation and determination (for reviews, see Akam 1987; Nüsslein-Volhard et al. 1987; Scott and Carroll 1987), dorsoventral positional information (Anderson and Nüsslein-Volhard 1986), and neurogenesis (Lehmann et al. 1983). However, Drosophila is a holometabolous insect; the adult form does not emerge from the growth of the embryo but from the complete metamorphosis of the larval imago. Relatively little is known about the genes that control adult pattern formation in the larval imaginal structures.

Some genes, particularly those of the Bithorax and Antennapedia homeotic class (Lewis 1978; Peifer et al. 1987), are known to affect both embryonic and adult segmental determination. Recessive loss-of-function homeotic gene alleles cause transformations of embryonic segment identity, whereas partial loss-of-function or dominant gain-of-function alleles may transform adult segmental fates. Molecular analyses of homeotic gene expression have shown that many homeotic genes are expressed throughout development, although it remains unknown as to how the expression of homeotic genes influences the external morphology of either embryonic or adult segments.

The hairy gene of Drosophila is another locus that affects both embryonic and adult pattern formation (Ingham et al. 1985). Early in embryogenesis, hairy acts as a pair-rule gene and controls the formation of pattern elements at double-segment intervals. It has been shown that a major part of hairy function is to control negatively the expression of the fushi tarazu (ftz) pair-rule gene. Mutations that disrupt early embryonic hairy activity cause a derepression of $f t z$ expression in regions where $f t z$ is not normally expressed (Carroll and Scott 1986; Howard and Ingham 1986), whereas ectopic induction of hairy can extinguish normal $\mathrm{ftz}$ expression (IshHorowicz and Pinchin 1987). Later in development, hairy is required to suppress ectopic bristle formation on many parts of the adult body. Ingham et al. (1985) have characterized four classes of hairy mutations, based on their complementation of the adult viable $h^{1}$ allele and an embryonic lethal allele. These four classes consist of alleles that (1) affect only the bristle pattern of adults; (2) affect bristle pattern and have weak effects on segmentation; (3) have some effect on bristle pattern and strongly affect segmentation; and (4) strongly affect both processes. Based on their genetic analysis, Ingham et al. (1985) proposed that the first three types of mutants probably identified different regulatory regions of the hairy gene controlling early and late expression of a common coding region. Mutations in the protein-coding region were presumed to cause the fourth most severe class of phenotypes.

hairy is the only pair-rule or gap gene besides giant (Simpson and Morata 1980) known to be required or expressed during later development. It is most likely that hairy is involved in a different regulatory pathway in imaginal structures than in embryos. Bristle development involves the differentiation of mechanosensory 
neurons of the peripheral nervous system (PNS). The ectopic bristle phenotype of adult viable hairy mutant and hairy ${ }^{-}$mutant clones induced by mitotic recombination suggests that the late hairy function is to suppress bristle formation. It is likely that part of this suppression is mediated through genes of the achaete-scute gene complex (AS-C), principally the achaete locus. Loss of achaete function mutations result in vast reductions in the number of small bristles (microchaete) on the adult body (for review, see Ghysen and Dambly-Chaudière 1988). In the presence of extra doses of achaete, hairy becomes dominant, i.e., extra bristles appear, indicating that the balance between the amount of the hairy and achaete gene products regulates the decision to form bristles in certain regions of the body (Botas et al. 1982).

To shed more light on the function of this key regulatory gene, previously we have studied its expression in embryos using specific antibodies (Carroll et al. 1988). hairy is expressed in a striped pattern of cell nuclei encircling the early embryo where it appears to regulate $f t z$ expression. Although hairy is expressed around the tracheal pits and a few other regions of the embryo at distinct times during embryogenesis, it is not expressed in the embryonic nervous system. Here, we show that hairy expression in imaginal discs is associated with morphogenetic events in the eye, leg, and wing and that it is lost or absent from cells that will differentiate into sensory structures. The striking spatial patterns of late hairy expression are associated with cell-cycle changes along several regions that will become morphological boundaries in the discs. The distinct patterns of hairy expression during morphogenesis suggest that hairy is under the control of other genes that specify positional information in the developing discs.

\section{Results}

We have investigated the pattern of hairy protein expression in many larval and pupal tissues by staining fixed whole-mount preparations with a hairy-specific antibody (Carroll et al. 1988). We find that hairy is expressed in all imaginal discs examined and in their tracheal branches. Here, we present detailed studies on the expression of hairy during the morphogenesis of the major imaginal discs.

The eye: hairy is transiently expressed in a line of cells anterior to the morphogenetic furrow as it traverses the disc

In surveying those third-instar larval imaginal discs that expressed hairy, we were surprised to observe that the highest level of hairy protein accumulation occurred in the eye portion of the eye-antennal disc (Fig. la). In middle to late third-instar discs, intense nuclear hairy staining is observed in a band three to five cells wide, stretching dorsoventrally across the entire apical surface of the eye disc. On the anterior side of this band, nuclei are visible that are expressing lower levels of hairy pro- tein (Fig. 1b, arrow). On the posterior side of the band, there is no trace of hairy expression.

Morphogenesis of the eye occurs as a wave across the disc epithelium (for review, see Tomlinson 1988). A depression in the disc surface, the morphogenetic furrow, moves across the third-instar eye disc from the posterior to the anterior (from the optic stalk toward the antennal part of the disc). Posterior to the furrow, the photoreceptor cells begin to differentiate and mitosis is restricted to a narrow band of cells, whereas the cells remain largely undifferentiated and continue to divide anterior to the furrow. To determine the position of the band of hairy staining relative to the morphogenetic furrow, we double-labeled eye discs with the rabbit antihairy antibody and the mouse monoclonal antibody $22 \mathrm{Cl0}$, which stains the developing axons of the photoreceptor cells (Fuiita et al. 1982). The morphogenetic furrow lies between the field of 22C10-labeled photoreceptor cells and the band of hairy expression (Fig. 1c).

Next, we sought to understand how hairy expression changed with respect to movement of the morphogenetic furrow. We double-labeled late second instar; early middle, and late third instar; and pupal eye discs with the hairy and $22 \mathrm{C} 10$ antibodies. The second-instar eye discs are very small, as several more rounds of cell division and growth occur during the third instar. The second-instar discs do not express much, if any, 22C10 antigen when the morphogenetic furrow is only $\sim 25 \%$ of the way across the eye disc, but they do express hairy in a band of cells across the disc and anterior to the morphogenetic furrow (Fig. 2a). By middle to late third instar, the morphogenetic furrow is $\sim 50 \%$ of the way across the disc and each antibody strongly labels cells on opposite sides of the furrow (Fig. 2b). In early pupal eye discs $[0-2 \mathrm{hr}$ after puparium formation, (APF)], the furrow is $\sim 60 \%$ of the way across the disc and the hairy staining is beginning to decrease anterior to the furrow (Fig. 2c). hairy protein is still detectable at $8 \mathrm{hr}$ APF in a thin band of cells at the far anterior end of the eye, near the base of the everting antennal disc (data not shown). From these staining patterns we can infer that hairy is expressed in cells as the furrow approaches and is then rapidly lost as the furrow reaches these cells and they differentiate into the various cells of the eye ommatidia. The weak level of hairy staining in nuclei six to eight cells anterior to the furrow and the absence of staining posterior to it indicate that both a hairy activation signal, as the furrow approaches, and a repression or destruction mechanism, to eliminate hairy from cells within the furrow, probably exist. The combined effect of activation and turnover or repression is the creation of a transient wave of hairy protein expression. On the basis of studies of morphogenetic furrow movement and ommatidial assembly (Ready et al. 1976; Campos-Ortega and Hofbauer 1977), which determined that the furrow moves one ommatidial row every $2 \mathrm{hr}$, we deduce that cells accumulate hairy for a period of $4-6 \mathrm{hr}$ and lose it within $30-45 \mathrm{~min}$.

Adult viable hairy mutants do not exhibit any discernible phenotype in the eye so we do not know the func- 


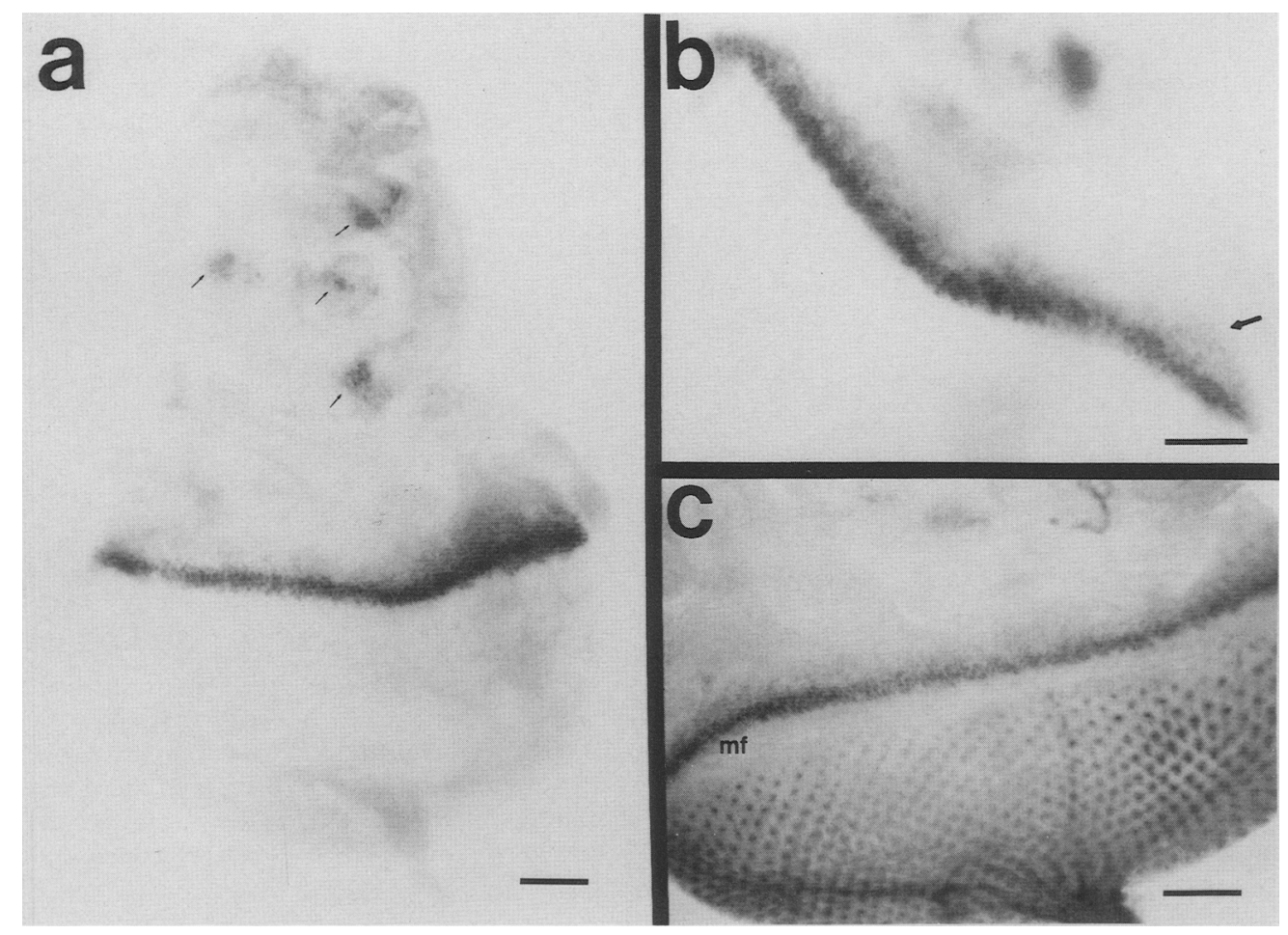

Figure 1. Expression of hairy protein in the third-instar larval eye-antennal imaginal disc. (a) Whole-mount eye-antennal disc stained with antibody to the hairy protein, as described in Methods. A line of hairy expression extends across the anterior portion of the eye disc (bottom), whereas several patches of hairy expression are discernible in the antennal portion of the disc complex (top, arrows). (b) Higher magnification view of hairy protein expression in the eye disc. There is strong expression of hairy in the cells on the posterior edge of the line (bottom), which has not yet become as strong in more anterior nuclei (solid arrow). Note the absence of any trace of hairy protein posterior (bottom) of the line. (c) Eye disc that was double-labeled with hairy antibody and monoclonal antibody $22 \mathrm{C} 10$. The anterior line of hairy staining (top) is separated from the field of developing photoreceptor cells stained with antibody $22 \mathrm{C} 10$ by the morphogenetic furrow (mf). Bars, $50 \mu \mathrm{m}$.

tion of hairy in the eye disc. $h^{1} / h^{1}$ homozygous larvae exhibit a normal spatial pattern of protein accumulation in the eye that appears to be just a small degree weaker than wild-type Oregon- $R$ larvae (data not shown). Perhaps the high residual level of hairy expression in $h^{1} / h^{1}$ mutant eyes is sufficient to provide full hairy function (see Discussion). Because strong hairy alleles are embryonic lethals, we must generate hairy- clones in the eye to assess what role, if any, the observed transient expression of hairy has in the proper development of the compound eye.

The leg: a complex spatial distribution hairy in third-instar discs emerges into a pattern of stripes during eversion of pupal discs

Many cells within each of the third-instar leg discs stain strongly with hairy antibody. In each compacted disc, only a subset of the total hairy pattern is discernible in any single focal plane; this is shown for the mesothoracic (second leg) disc in Figure 3, a-c. hairy-labeled cells are found within most or all of the presumptive leg segments (for a general fate map of the leg, see Bryant 1975, 1978) in various sized patches and concentric rings of cells that follow the contours of the folds within the disc. Because of these folds and the thickness of the structure, out-of-plane staining appears as fuzzy gray to black clouds. Optical sectioning of the disc resolves many of these clouds when the appropriate focal plane is reached (Fig. 3a-c). The prothoracic (first leg) and metathoracic (third leg) discs exhibit patterns that are similar to the mesothoracic leg (Fig. 3d,e). The different sizes and contours of the legs make it difficult to establish whether there are exact correspondences between hairy expression in each leg at this state of development. After eversion, we can determine some relationships more clearly.

Shortly APF, the leg discs begin to unfold and evert to produce an elongated tubular structure (for details, see Fristrom and Fristrom 1975; Fristrom 1976). The center of the larval disc forms the most distal elements of the pupal leg, the tarsal segments. During eversion, the concentric rings of hairy expression evolve into longitudinal rows and transverse patches of stained cells (Fig. $4 \mathrm{a}-\mathrm{c}$ ). From the examination of staged leg discs, it appears that the level of hairy expression is increasing during early evagination, with some cells becoming more intense and others turning on hairy. As each leg disc everts, it can be 


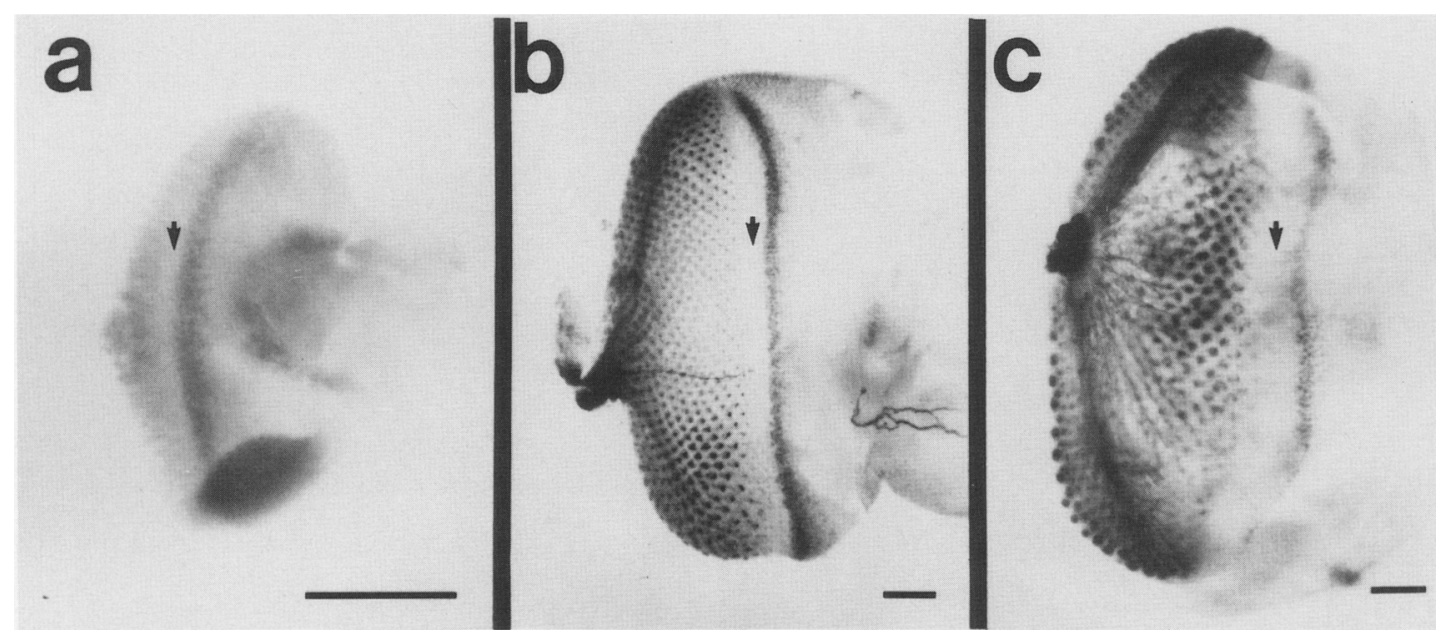

Figure 2. The fate of hairy protein expression during eye development. Eye discs at different stages of development were doublelabeled with the hairy and $22 \mathrm{C} 10$ antibodies. Arrows indicate the position of the morphogenetic furrow in each disc as it moves from the posterior (left) to the anterior (right). (a) Second-instar larval eye disc with furrow $\sim 25 \%$ of the distance across the disc. There is little or no $22 \mathrm{C} 10$ staining posterior to the furrow, but there is hairy expression in a line anterior to the furrow. Note the relative size of this disc compared to the older discs. (b) Third-instar larval eye disc with furrow $\sim 50 \%$ of the distance across the disc. There is strong expression of both the $22 \mathrm{C} 10$ antigen within the developing photoreceptor cells posterior to the furrow and the hairy protein in the undifferentiated cells just anterior to the furrow. (c) Early pupal eye disc with furrow $\sim 60 \%$ of the distance across the disc. The hairy line has moved and remains anterior to the morphogenetic furrow. Bars, $50 \mu \mathrm{m}$.

seen that the overall patterns of hairy expression are similar. Each leg exhibits four rows of cells along the longitudinal axis of the femur and tibia that continue both proximally toward the coxa and distally into the basitarsus and the four other tarsal segments (Fig. 4a-c, see corresponding lines between tibia and tarsal segments). In the tarsal segments, there are both transverse rings and patches of cells that are oriented perpendicularly to the longitudinal rows. One ring is most evident in the fourth tarsal segment (Fig. 4a,b). The overall hairy expression patterns are similar between the different pupal legs in that the main longitudinal lines are present consistently. The slightly different shapes of each leg and the lack of an independent constant landmark make it difficult to determine whether there are strictly conserved elements to each leg pattern. However, the types of cells that express hairy are very constant from leg to leg (see below).

\section{hairy is excluded from leg neurons}

A major question concerning hairy function deals with the types of cells that express it. The ectopic bristle phenotype of adult viable homozygous mutants and the hairy genetic interaction with the AS-C suggests that hairy works to oppose neuronal determination that is positively controlled by the AS-C (Botas et al. 1982; Ghysen and Dambly-Chaudiere 1988). During late larval and early pupal development, much of the adult PNS is formed. We have examined the spatial relationship of hairy expression to these events in the leg and wing.

By $4 \mathrm{hr}$ APF, many neurons and their axons are clearly evident in the developing legs. The monoclonal antibody $22 \mathrm{C} 10$ labels the axons extended by all peripheral neu- rons. We double-labeled pupal legs with anti-hairy and the $22 \mathrm{C} 10$ antibody to determine the relationship between the peripheral neurons and hairy expression. hairy is not expressed in 22C10-labeled cells in all legs at all times. This relationship is clearest when one inspects the pattern of hairy staining in the tarsal segments of a well-everted leg disc. In many places, there are patches of cells exhibiting high levels of hairy staining but one or two cells in the patch are unlabeled (Fig. 5a, arrows). Some cells that do not express hairy are labeled by $22 \mathrm{Cl0}$ (Fig. 5b, arrows). We have not been able to determine whether these neurons differentiate from what were previously hairy-expressing cells or whether all neuronal precursors are set aside before the hairy pattern is established. On the basis of the spatial relationship of the hairy-expressing cells to the leg neurons (for a high magnification view, see Fig. $5 \mathrm{c}$,d) and the fact that hairy staining in the larval leg precedes neuronal differentiation in the pupal leg, it is possible that the neurons are born from cells that may have once expressed hairy.

The wing: hairy is expressed along the presumptive wing veins and excluded from peripheral neurons

The third-instar wing and haltere discs consistently exhibit weaker levels of hairy expression. This is not due to problems with the penetration of antibodies, because other nuclear antigens are well stained in our protocols. In the wing, there are several areas that are lightly labeled by the hairy antibody (Fig. 6a). These include a large portion of the thoracic region of the disc that will give rise to parts of the notum (Fig. 6a, th). The staining pattern is less distinct but above background on the ven- 


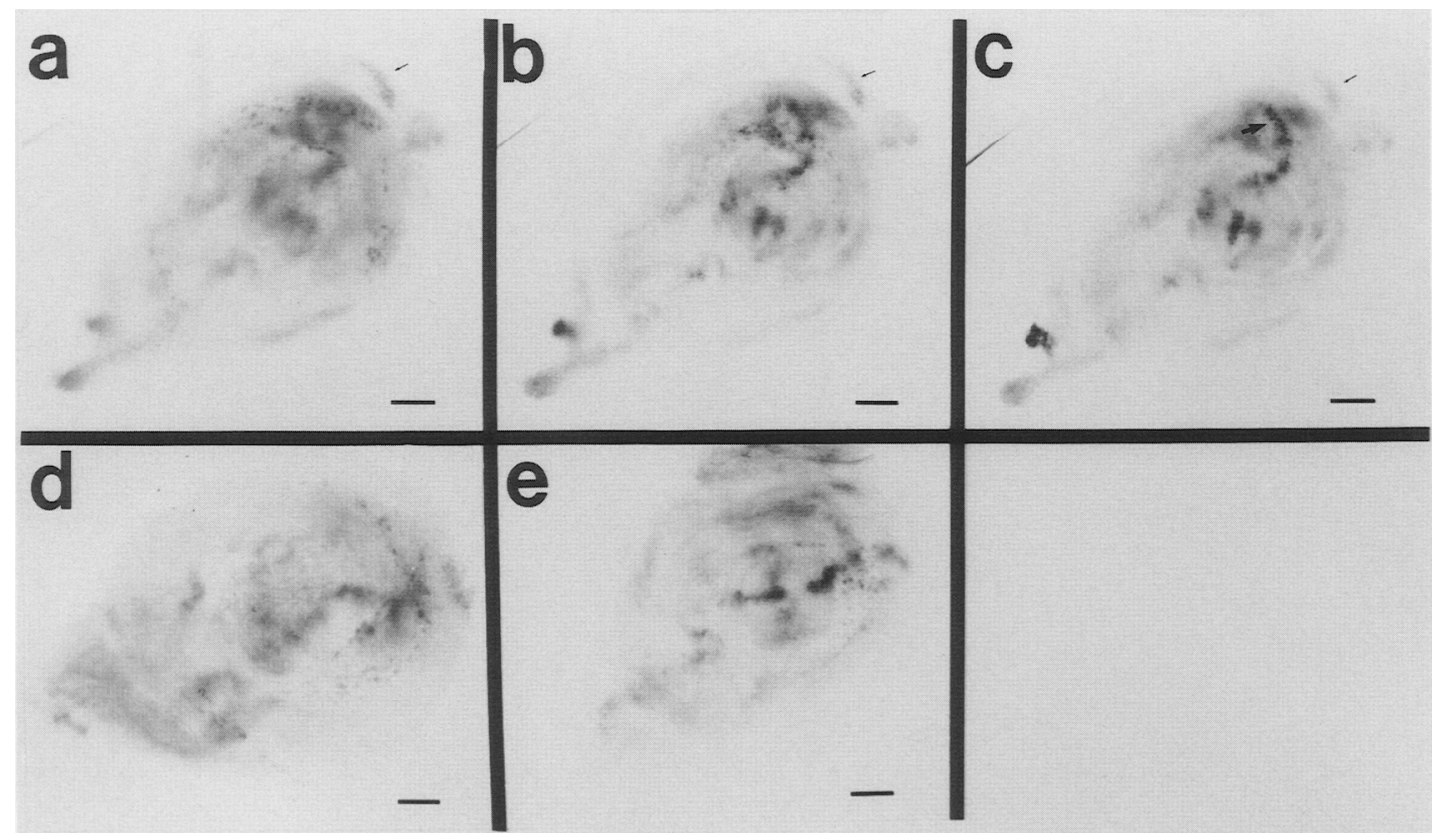

Figure 3. The patterns of hairy expression in larval leg imaginal discs. In all frames, proximal is to the left and distal is to the right. $(a-c)$ Different focal planes through a mesothoracic leg disc stained with hairy antibody. The more proximal focal plane exhibiting the outer concentric rings of hairy expression is shown in $a$; the more distal plane is shown in $c$. Note the change in the clarity of the patch of hairy-labeled cells as the focal plane moves distally (small arrow). As the distal focal plane is reached, the tarsal segments of the leg come into focus; sharp nuclear staining can be observed in regions that appear fuzzy gray when out of focus (large arrow in $c$ ). (d) Prothoracic leg disc, proximal focal plane. Overall, there is a resemblance to the spatial pattern of hairy expression in $a$; however, it is impossible to determine whether there is precise correspondence between the two leg discs. (e) Metathoracic leg disc, distal focal plane. There is a resemblance to the pattern shown in $e$, but a precise comparison is not possible. The dark nuclei toward the center of the disc belong to the tarsal portion of the disc. Bars, $50 \mu \mathrm{m}$.

tral portion of the disc, near the region that will serve as the wing hinge between the dorsal and ventral surfaces of the wing and near the midline of the wing blade. Both the lower level of staining and the contours of the folds within the disc hinder a more precise determination of the hairy pattern at this stage of development.

As the wing disc everts, part of the spatial pattern of hairy expression becomes much clearer and stronger.. By $6 \mathrm{hr}$ APF, hairy is clearly visible in two longitudinal lines across the dorsal surface of the presumptive wing blade (Fig. 6b), as well as in patches in the thorax (data not shown). On the basis of the position of these lines with respect to the rows of neurons that form along the anterior wing margin on longitudinal vein $\mathrm{Ll}$ and the three neurons that arise early on L3 (Murray et al. 1984), we can place these lines of hairy expression along the 'preveins' of L2 and L3. By $8 \mathrm{hr}$ APF, the L3 staining is the most prominent (Fig. $6 \mathrm{C}$ ). We double-labeled pupal wing discs with both hairy antibody and the neural-specific monoclonal antibody $22 \mathrm{C} 10$ to examine the spatial relationship of neuronal differentiation to hairy expression. As was the case in the legs, some cells in the longitudinal rows along L 3 that do not express hairy, but are surrounded by hairy-containing cells (Fig. 6d, arrows), are labeled with the $22 \mathrm{Cl} 0$ antibody (Fig. 6e, arrows).

These observations are the most relevant with respect to previous descriptions of the hairy mutant phenotype.
In homozygotes for adult viable alleles, such as $h^{1}$, ectopic bristles are observed on the wing blade, predominantly along veins L2 and L3 (Ingham et al. 1985). The expression of hairy in the cells that will form these veins certainly correlates with the genetic requirement for hairy to suppress ectopic bristle formation in L2 and L3. The comparatively low level of hairy expression in the preveins suggests that these structures may be very sensitive to a reduction in hairy ${ }^{+}$function and could largely explain why the hairy mutant phenotype is most evident in the wings and not on the legs or eyes, where much higher levels of hairy protein accumulate. We examined hairy protein accumulation in homozygous $h^{1} / h^{1}$ larvae and pupae and observed essentially identical patterns to those in the wild-type eye, leg, and wing (Fig. $4 \mathrm{~d})$. However, it appeared that there was a slight reduction in the amount of hairy antigen in some mutant discs. This reduction could partially explain the $h^{1} / h^{1}$ phenotype and the sensitivity of the wing bristle pattern to hairy and AS-C dosage (see Discussion).

The extent of hairy protein expression APF was unexpected also. Previous studies on the requirement for hairy in suppressing bristle development in clones of cells induced during larval and pupal life concluded that hairy was not required beyond $8 \mathrm{hr}$ before puparium formation (BPF) (Garcia-Bellido and Merriam 1971). There may be several explanations why hairy could appear to 


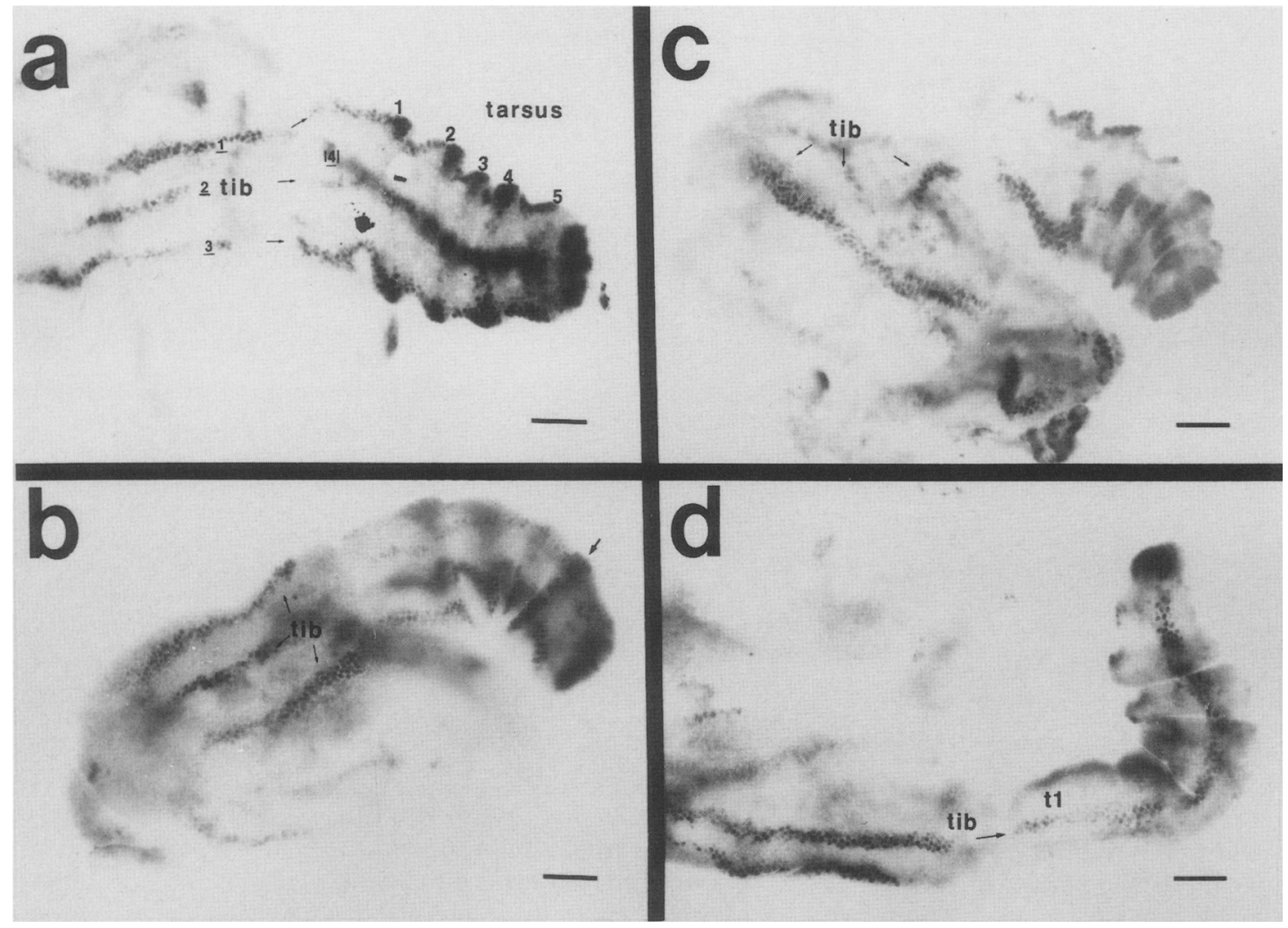

Figure 4. Emergence of an ordered hairy pattern during eversion of pupal imaginal leg discs. In all frames, proximal is to the left and distal is to the right. (a) Prothoracic leg disc $4 \mathrm{hr}$ APF. There are four longitudinal lines of hairy expression. Three lines (1-3) in the tibia (tib) are in focus and extend in a discontinuous pattern into lateral $(1,3)$ and medial $(2)$ regions of the tarsal segments $($ small arrows). A fourth line (4) is located medially but is out of focus on the opposite side of the disc. There are five tarsal segments $(1,5)$; the fourth exhibits a strong transverse band of hairy staining. (b) Mesothoracic leg disc $4 \mathrm{hr}$ APF. Three of four longitudinal lines of hairy expression are in focus in the tibia (tib, small arrows); these are similar to the lines in $a$. In the fourth tarsal segment, there is also a large transverse band of hairy expression (arrow) as in the prothoracic leg above. (c) Metathoracic leg disc $4 \mathrm{hr}$ APF. Three of the four longitudinal lines of hairy expression are visible in the tibia (tib, small arrows). The tarsal pattern resembles those of the prothoracic and mesothoracic leg discs above. (d) Leg disc from homozygous $h^{1} / h^{1}$ pupa $7 \mathrm{hr}$ APF. The level of hairy expression is comparable to that found in wild-type animals. Note the long line of hairy expression extending from the proximal tibia to the tip of the tarsus. Bars, $50 \mu \mathrm{m}$.

be required early and still be expressed at such high levels later in development. First, induction of somatic clones does not reveal the time of gene action directly. In this case, $8 \mathrm{hr}$ BPF was the point beyond which induction of $h^{1} / h^{1}$ homozygous clones had no effect on bristle phenotype. Because the $h^{1}$ allele is only a weak allele and the hairy protein probably has a significant half-life, it is possible that sufficient hairy protein exists for many hours in 8-hr BPF clones to suppress bristle formation. We cannot determine the moment of bristle determination and the hairy function in that process until more is known about where hairy is expressed in relation to the bristle progenitor cells. Second, it is quite conceivable that some function(s) of hairy is unrelated to bristle development per se. Clearly, the eye function may involve a different type of neuronal regulation. Some of the leg or wing patterns may be involved in other pathways. Either analysis of cell clones for null hairy alleles or identification and study of hairy mutations that abolish hairy function in the imaginal discs will be required to evaluate these possibilities.

\section{Relationship between hairy expression and compartmental boundaries}

The stripes of hairy-expressing cells in the leg and wing prompted us to consider whether these patterns reflected determinative boundaries in the discs. In the wing, it has been shown previously that the $\mathrm{L} 3$ veins and the anterior-posterior (A-P) boundary are not coincident (Schubiger and Palka 1987). We can conclude from these studies that the L2 and L3 hairy patterns lie within the anterior compartment of the wing.

In the leg, however, little information exists regarding lineage boundaries. To study the relationship of hairy expression to compartmental boundaries, we double-labeled pupal leg discs with hairy antibody and a monoclonal antibody to the engrailed (en) gene product, which serves as a definitive marker of the posterior compartment (DiNardo et al. 1985; Kornberg et al. 1985). We examined several 6-hr APF leg discs in detail and observed a very consistent relationship between the hairy and en protein patterns. In all legs, it could be de- 


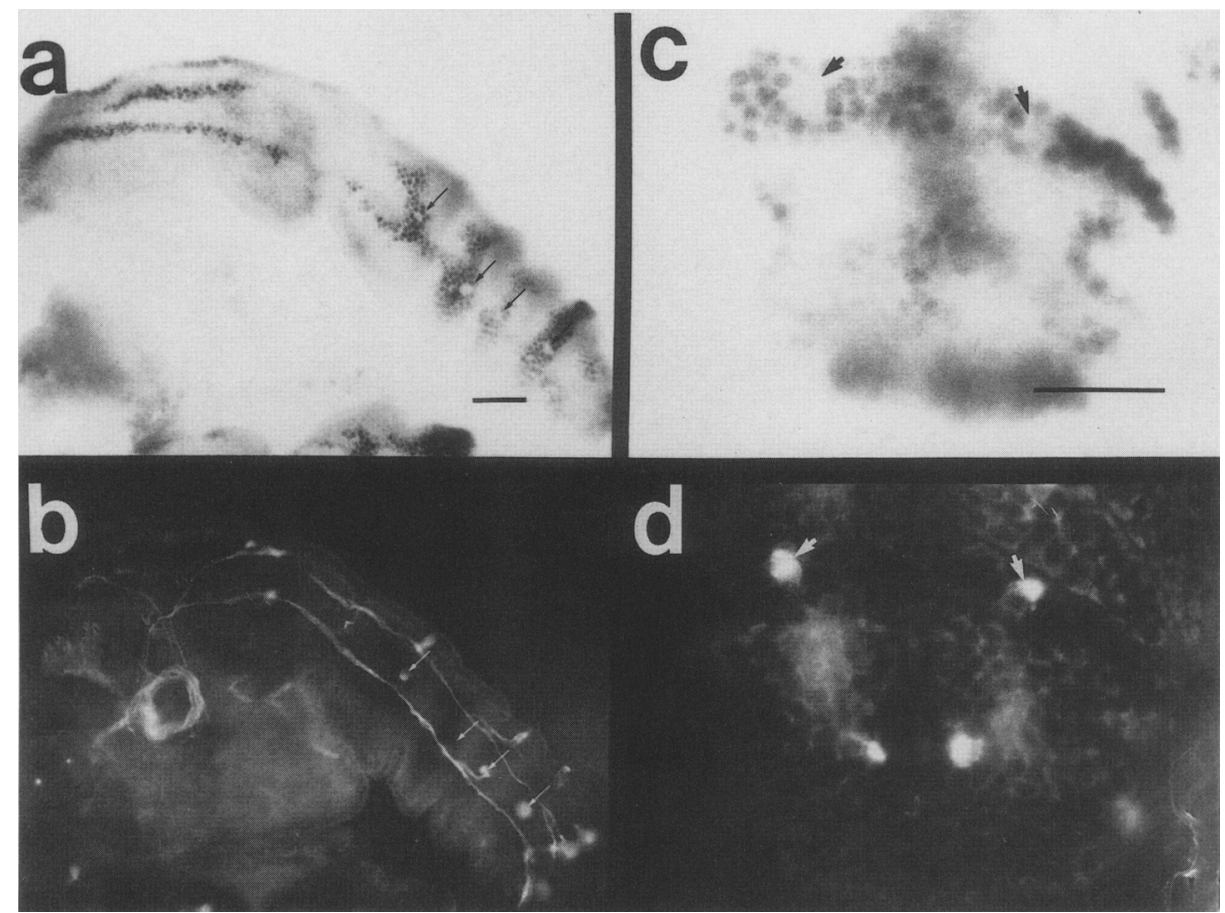

Figure 5. Exclusion of hairy expression from pupal leg disc neurons. Prothoracic pupal leg discs 5 hr APF were double-labeled with hairy and $22 \mathrm{ClO}$ antibodies and were visualized by bright-field (hairy, $a, c)$ and fluorescence $(22 \mathrm{C} 10, b, d)$ microscopy. $(a)$ Leg disc exhibiting typical hairy staining pattern. Note the holes in the patches of staining on several tarsal segments (arrows). (b) Same leg as in $a$ stained with $22 \mathrm{Cl0}$. The holes observed in $a$ include neurons labeled by this antibody (arrows). (c) High magnification view of hairy expression in distal tarsus. Two holes in the hairy-labeled patch in T4 are indicated (arrows). (d) Same view as in $c$; the $22 \mathrm{Cl0}$ pattern indicates that the holes in $c$ include neurons labeled by $22 \mathrm{C} 10$ (arrows). Bars, $50 \mu \mathrm{m}$.

termined that of the four longitudinal lines of hairy expression, some were located entirely within and some completely outside of the en domain (Fig. $7 \mathrm{a}, \mathrm{b}$ ). There is no strict relationship between the proteins; hairy is not simply following the A-P compartmental lineage restrictions. Of the four hairy lines, one runs within the posterior compartment (line 1 in Fig. $7 \mathrm{a}-\mathrm{d}$ ), one runs along the A-P boundary (line 2 in Fig. $7 a-d$ ), and two lie well within the anterior compartment (arrows in Fig. 7a,b; line 3 in Fig. $7 \mathrm{c}, \mathrm{d})$. The orientation of the hairy-labeled rows and the en pattern suggests that the rows are established by a regulatory mechanism that operates parallel to the orientation of the A-P boundary. Some of the segment polarity genes that affect disc development (e.g., wingless, hedgehog) could be involved in the regulation of the spatial pattern of hairy expression in these longitudinal stripes. The regulation of hairy in discs must operate differently from the embryo; most gap and pairrule segmentation genes are inactive during late development.

\section{Discussion}

We have shown that the nuclear product of the hairy embryonic segmentation gene is expressed in a striking array of patterns during the morphogenesis of the eye, leg, and wing imaginal discs. Several of these patterns were completely unexpected, as previous analyses of hairy mutant flies had given little indication of the extent and nature of hairy gene expression during disc development. Our observations have several implications regarding the general role of the hairy protein in controlling the spatial pattern of PNS development, the nature of the genetic regulatory program that specifies positional information during metamorphosis, and the general relationship between hairy gene expression, disc cell-cycle changes, and the commitment to cell differentiation during disc morphogenesis.

\section{Spatial and temporal regulation of hairy protein expression}

The complete cycle of hairy protein expression [which we believe to involve only one species of polypeptide (I. Langeland and S. Carroll, unpubl.)]-first in transverse stripes encircling the embryo, then in small clusters of cells surrounding the embryonic tracheal pits, and later in the patterns described here during disc morphogenesis-illustrates an important emerging theme from the developmental and molecular analysis of Drosophila pattern-regulating genes. Namely, a single regulatory protein (and its potential post-translationally modified subforms) is deployed frequently in several distinct spatiotemporal patterns during the course of development and may control and be controlled by unique sets of genes at each stage and in different tissues. Several other 


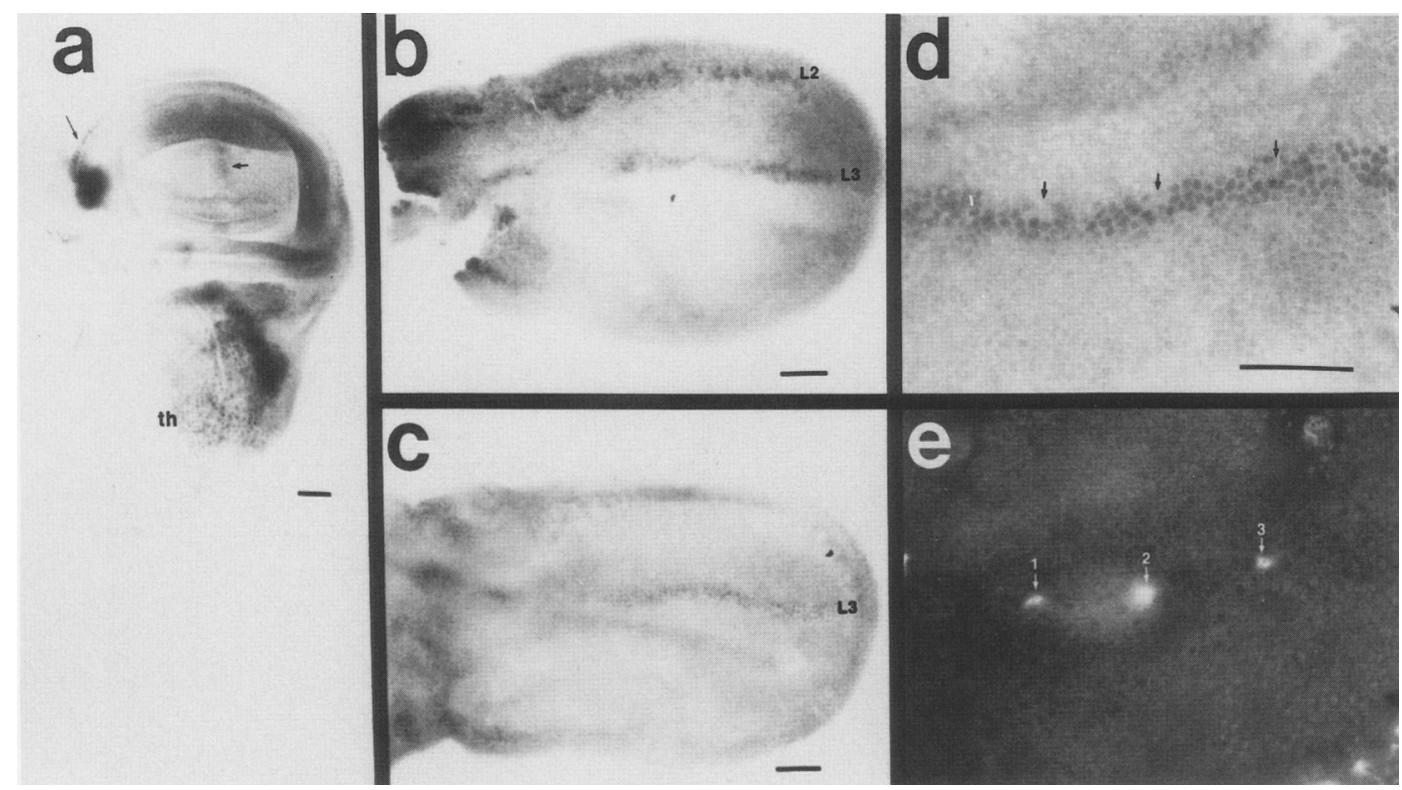

Figure 6. Expression of hairy during wing disc development. (a) Third-instar larval wing disc labeled with hairy antibody. Antigen levels are generally weak and can only be discerned within the thoracic (th) region of the disc and in diffuse patterns near the distal end of the disc (long arrow) and the midline of the presumptive wing blade (short arrow). (b) Wing disc 6 hr APF. Only the everted blade portion of the disc is shown. hairy expression is evident on the dorsal surface along the presumptive longitudinal wing veins $\mathrm{L} 2$ and L3. (c) Wing disc $8 \mathrm{hr}$ APF. The disc blade is beginning to expand with hemolymph. L3 staining is clearly evident, and L2 staining is out of this field of view. There appear to be very weak levels of hairy expression in the more posterior (bottom) preveins of the disc. (d) High magnification view of L3 staining in C. Along the row of hairy-expressing cells are a few obvious gaps in staining (arrows); these include the three dorsal sensory neurons (see $e$ below). (e) The disc in $d$ was double labeled with $22 \mathrm{Cl0}$ antibody and exhibits three individual neurons (arrows) that are located within the gaps observed in the hairy pattern in $d$. Bars, $50 \mu \mathrm{m}$.

important pattern-regulating genes have been shown to be regulated independently and/or expressed in different tissues, including the ectoderm versus the central nervous system [e.g., ftz, en, even-skipped (eve) (Carroll and Scott 1985; DiNardo et al. 1985; Hiromi et al. 1985; Frasch et al. 1987)]; the ectoderm versus the PNS [e.g., Antennapedia (Carroll et al. 1986; Boulet and Scott 1988)]; or the ectoderm versus the mesoderm [e.g., U1trabithorax (Akam and Martinez-Arias 1985; Bienz et al. 1988)]. The hairy pair-rule stripes are controlled by gap and pair-rule genes in the blastoderm embryo, but because these genes are inactive during disc morphogenesis, the pattern of hairy disc stripes must be generated by a different regulatory system. Elucidating the cis-and trans-acting regulatory machinery that generates such developmentally complex gene expression will be an important step toward understanding the functional roles of pattern-regulating genes.

Given the varying levels and duration of hairy expression in the different discs and the apparently unique spatial coordinates of each pattern in the three major discs, it is likely that the regulation of the hairy locus during disc morphogenesis is complex and involves multiple cis-acting elements and trans-acting factors. This notion is supported by several additional observations, including (1) the profile of RNA transcripts from the hairy locus changes during development and could involve multiple promoters and alternative RNA splicing patterns (Ish-Horowicz et al. 1985); (2) adult viable mu- tations map outside of the coding region and range up to $20 \mathrm{~kb}$ away from the $5^{\prime}$ end of the gene (Holmgren 1984; Howard et al. 1988); and (3) the embryonic regulation of hairy involves distinct cis-acting elements that are distributed over $10 \mathrm{~kb}$ upstream of the gene (Howard et al. 1988); these elements are most probably acted on by completely different factors (e.g., gap and pair-rule gene products) than the disc pattern elements. If disc patterncontrolling DNA elements are nested between and around the embryonic stripe-regulating elements, then a large region of DNA may be required for proper spatial control. It is also possible that some aspects of hairy control, e.g., its rapid turnover in the morphogenetic furrow, could be regulated post-transcriptionally at the level of mRNA or protein stability.

\section{Function of the hairy protein during disc morphogenesis}

There are two different aspects to understanding hairy function in imaginal disc development. First, we may consider what hairy's role is in the morphogenesis of a particular disc. For example, the eye develops in a fairly distinct manner from the legs or the wing. The developmental timing orchestrated by the morphogenetic furrow (and reflected by hairy expression) does not appear to have a counterpart in the discs of the body appendages. Second, we may consider the overall role of hairy that is common to each disc, e.g., its apparent general function in regulating the spatial pattern of PNS de- 


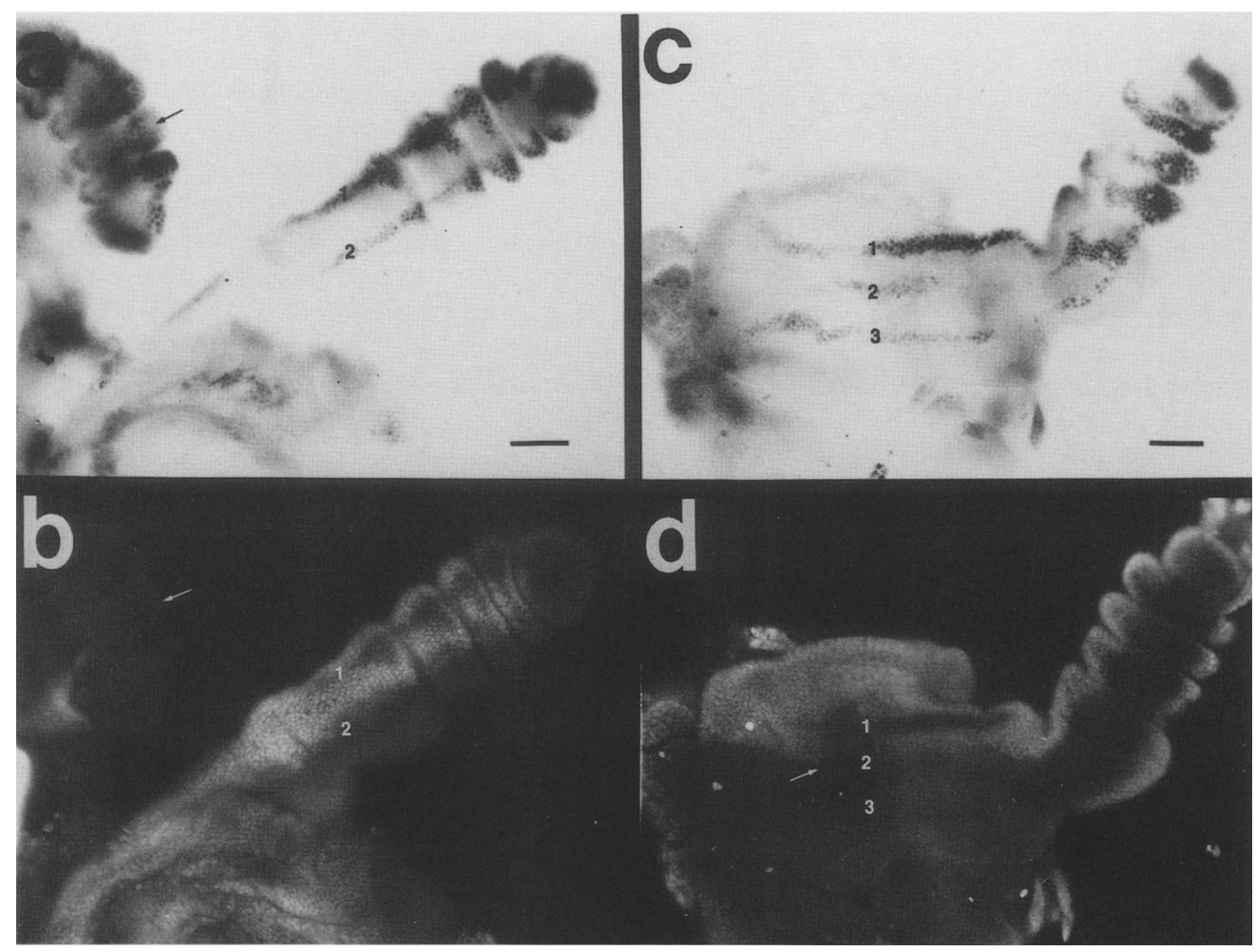

Figure 7. The relationship between the hairy spatial pattern and compartmental boundaries defined by en expression. Pupal leg discs were double-labeled with hairy antibody and a monoclonal antibody to the en gene product (gift of N. Patel). (a) hairy expression in the tarsus of a pair of pupal prothoracic leg discs $(6 \mathrm{hr}$ APF). Two lines of hairy expression are visible along the lateral region of the right leg $(1,2)$, and one line is visible in the leg at the upper left (arrow). (b) en expression in leg shown in $a$. Note that line 1 in $a$ cuts through the middle of the en-labeled region of the right leg, whereas line 2 abuts the en pattern. The deposition of DAB shown in $a$ quenches the rhodamine fluorescence signal in $b$, accounting for the dark shadows on the image. Note that there is no en expression in the area stained by hairy in the left leg (arrow); this hairy line is in the anterior compartment of the leg. $(c, d)$ Another prothoracic leg disc $6 \mathrm{hr}$ APF. This view highlights three femur-tibia lines of hairy expression across a more proximal portion of the disc. By double labeling with en antibody in $d$, it can be seen that line 1 lies entirely within the en pattern, line 2 abuts it, and line 3 is outside of it. Bars, $50 \mu \mathrm{m}$.

velopment. We will discuss these points in the context of each disc's particular pattern of development.

\section{The eye}

The hairy protein expression in the eye disc was unexpected because no hairy mutants or clones of mutant cells have been shown to affect eye development. The anterior position of hairy expression with respect to the morphogenetic furrow is also unusual in that most eye antigens described previously have been restricted to the cells posterior to the furrow (Zipursky et al. 1984; Banerjee et al. 1987; Tomlinson et al. 1987). Because the line of hairy protein moves anteriorly as the furrow passes across the eye, it is clear that each set of photoreceptor cells transiently express hairy before they pack basally in the furrow, differentiate, and move to the apical region of the epithelium (for a review, see Tomlinson 1988). There is a relationship between hairy expression and cell behavior; loss of hairy expression is associated with the commitment to differentiate into an ommatidial cell type. We are attempting to investigate further hairy's function in the eye by examining the behavior of hairy- clones induced during larval development.

Whatever the precise molecular function of hairy may be in the eye, we point out that it must be different than when hairy is expressed in transverse stripes of nuclei around the cellular blastoderm embryo. During early embryogenesis, hairy is a regulator of the pair-rule genes ftz (Howard and Ingham 1986; Carroll and Scott 1986), eve (Frasch and Levine 1987) and runt (Ingham and Gergen 1988|. No larval function for these pair-rule genes has ever been indicated, and we have confirmed that $f t z$ and eve are not expressed in larval or pupal tissues (data not shown). Thus, the regulatory functions of these pair-rule genes diverge in later development, as well as in the embryonic central nervous system (Doe et al. 1988a).

\section{The wing and leg}

The wing and leg hairy patterns emerge most clearly during the first $6 \mathrm{hr}$ of pupation. The expression in the wing disc is most germane to the interpretation of the 
hairy mutant phenotype, as most previous studies have focused on the ectopic bristle phenotype on the notum and wing blade. We observed expression of hairy in both the notum and along the preveins of L2 and L3. These are also the positions that are most affected by mutations in the hairy locus or by a reduction in hairy dosage (Botas et al. 1982; Ingham et al. 1985).

Although there is a correlation between the phenotype of hairy mutants and the spatial distribution of hairy protein, we must explain why these sites are more sensitive to a reduction of hairy ${ }^{+}$activity than the eye or leg. There are three reasonable explanations: (1) These sites may express a more critical balance of hairy to bristle-determining gene products (e.g., achaete); (2) hairy may have a different function in the eye and leg than in the wing; or (3) the more trivial possibility is that these sites yield a phenotype that is scored more easily. We strongly favor the first explanation because there is no doubt that wild-type wing and notal cells naturally express lower levels of hairy protein than the eye or leg cells do. If hairy ${ }^{+}$is in balance with opposing gene functions, such as achaete ${ }^{+}$, it follows that even a slight reduction in hairy ${ }^{+}$activity could produce a phenotype in places where expression is required, but is naturally low (e.g., the wing). We observe high and near wild-type levels of hairy protein in eye and leg discs from $h^{1 / h^{1}}$ larvae and pupae; either those discs express sufficient hairy to carry out its complete function or, as mentioned above, perhaps hairy has a different function in the legs and eyes.

The high-level expression of hairy in the longitudinal rows of pupal leg cells was also surprising, as there is no clearly discernible phenotype of $h^{1} / h^{1}$ adult legs. In addition, the even spacing of these lines suggests that hairy is respecting the spatial coordinates of some regulatory system that subdivides the legs into smaller developmental units. It has been noted that the leg bristles are largely organized into longitudinal rows (for a review, see Held and Bryant 1984). The rows of bristles and the rows of hairy protein probably reflect the same underlying system of positional information; however, what is the relationship between them? Unfortunately, because of adverse changes in the properties of leg discs by $12 \mathrm{hr}$ APF and later (secretion of cuticle, swelling with hemolymph|, we were unable to pursue the analysis of hairy expression at the time of bristle determination. However, based on the exclusion of hairy from those leg neurons present by $4-8 \mathrm{hr}$ APF, we would expect that either hairy expression must be lost by the time of bristle determination or that the hairy stripes run parallel to the rows of cells that give rise to bristles. It is possible that the four lines of hairy expression demarcate four of the eight stripes of naked cuticle separating the eight bristle rows that can be seen, for example, in the basitarsus (first tarsal segment) of the adult second leg. We are attempting further developmental studies to resolve this point.

Relationship between hairy expression, the cell cycle, sensory neuron differentiation, and overt morphology

The observed pattern of hairy expression in imaginal discs suggests a possible relationship between the spatial pattern of DNA replication and hairy protein distribution. Several previous studies have indicated a relationship between changes in cell cycles and the position of morphological boundaries. In the eye disc, cells exist in a pattern of asynchronous divisions far ahead of the morphogenetic furrow, undergo little DNA synthesis, six to eight cell rows just anterior to and including the furrow, and resume replicative activity posterior to the furrow. Cells posterior to the furrow differentiate into the ommatidial precursors, whereas cells anterior to the furrow are yet to be recruited into these structures. (The preceding descriptions were based on Ready et al. 1976; and Tomlinson 1985). The expression of hairy appears to be coupled to these events in that the nonreplicating cells anterior to the furrow are those that are accumulating hairy, whereas the adjacent basally localized differentiating cells in the furrow have lost all traces of hairy protein.

In the wing disc, Schubiger and Palka (1987) have described the distinct spatial patterns of S-phase nuclei and have shown that different fields of cells enter an extended $G_{2}$ phase at different times of development. A zone of nonproliferating cells runs down the midline of the third-instar wing disc and corresponds to the rows of cells that will make up the L3 vein. hairy protein accumulates in these cells during the first several hours APF. By 3-4 hr APF, the nuclei of the wing blade are no longer replicating DNA and most have a tetraploid DNA content (Fain and Stevens 1982; Graves and Schubiger 1982), reflecting that they are in $G_{2}$ phase and have not undergone mitosis. During this period, morphogenetic movements occur for disc eversion, and neurons differentiate and extend their axons which are essentially the preveins of the wing. By $12 \mathrm{hr}$ APF, the L 3 cells and other veins re-enter $S$ phase, whereas most intervein cells are still quiescent. Schubiger and Palka (1987) proposed that the step out of $S$ phase is the first sign of cells beginning their commitment to participate in differentiative events in the wing, which for the midline (L3) cells involves formation of the L3 prevein, guidance of axons, and eventually the elaboration of the adult vein pattern. Because vein formation is normal in hairy ${ }^{-} \mathrm{mi}^{-}$ totic clones (Ingham et al. 1985) and the three principal dorsal L3 sensory neurons are born before the hairy pattern is elaborated (Fig. 6), we do not believe that hairy expression is driving vein formation but that it is somehow responding to this process.

One final point to consider concerns the relationship between hairy expression and the commitment to differentiate a neuron. In the eye, the sequence of events is clear: hairy is lost before differentiation is manifest. If we assume that hairy is behaving as a genetic regulatory protein, then hairy could be involved in repressing (even transiently) that commitment. In the wing, it appears that some neurons are specified before hairy even starts to accumulate to higher levels, yet ectopic bristles will appear if hairy function is reduced or lost. Perhaps, in the wing and legs, hairy serves more of a maintenance function to prevent epithelial cells from differentiating into neurons, whereas in the eye, hairy may be required 
for the synchronization of the wave of ommatidial differentiation. One of the more promising avenues for resolving the regulatory function of hairy in neuronal determination would be to pursue the basis for its interaction with achaete (Botas et al. 1982). A better understanding of the genes driving neuronal determination in imaginal discs could yield helpful clues to the relationship between hairy function and cell behavior.

\section{Methods}

Stocks

Wild-type Drosophila melanogaster (Oregon R) was raised at $18-20^{\circ} \mathrm{C}$. To select individuals of specific ages, the following staging methods were used: For second-instar larvae, animals were collected 50-65 hr after egg deposition; for middle to late third-instar larvae, wandering-stage animals were collected off bottle walls; for pupae, white-stage prepupae $(0-\mathrm{hr}$ puparium formation) were collected and aged for controlled time periods on moist filter paper at $18^{\circ} \mathrm{C}$.

\section{Fixation and antibody staining}

The overall technique is very similar to that described by Brower (1987). Larval or pupal heads were pulled or cut off, and extraneous tissues such as trachea, fat body, and salivary glands were removed so that penetration of the reagents was more uniform.

The tissues were fixed for $20 \mathrm{~min}$ in $0.1 \mathrm{M}$ PIPES ( $\mathrm{pH}$ 6.9), 2 $\mathrm{mM} \mathrm{MgSO}_{4}, 1 \mathrm{~mm}$ EGTA, and $1.0 \% \mathrm{NP}-40$, containing $1 \%$ formaldehyde $(\mathrm{vol} / \mathrm{vol})$. After fixation, the tissue was blocked for $1-8 \mathrm{hr}$ at $4^{\circ} \mathrm{C}$ in $50 \mathrm{~mm}$ Tris- $\mathrm{HCl}(\mathrm{pH} 7.4), 150 \mathrm{~mm} \mathrm{NaCl}$, and $0.5 \%$ NP-40, containing $5 \mathrm{mg} / \mathrm{ml}$ bovine serum albumin (BSA). All antibody incubations and washes were in this buffer at $4^{\circ} \mathrm{C}$, except the BSA concentration was reduced to $1 \mathrm{mg} / \mathrm{ml}$. All transfers were done by moving the heads from well to well with forceps.

After blocking, the tissues (three to four larval or pupal heads) were incubated overnight in $200 \mu \mathrm{l}$ of antibody solutions in individual wells of 48-well tissue-culture dishes. Affinity-purified rabbit anti-hairy antibody (Carroll et al. 1988) was used at 3 $\mu \mathrm{g} / \mathrm{ml}$, whereas monoclonal antibody $22 \mathrm{C} 10$ supernatant was used at a dilution of $1: 200$ for rhodamine double-labeling experiments and at $1: 1500-1: 3000$ for peroxidase-based double-labeling experiments. Monoclonal anti-en antibody (gift of Nipam Patel) was diluted 1:10. The heads were washed with four changes of the incubation buffer over $90 \mathrm{~min}$ and then incubated in the appropriate secondary antibodies for $2 \mathrm{hr}$. These include biotinylated goat anti-rabbit IgG (Vector) or biotinylated goat anti-mouse IgG (Vector) at $4 \mu \mathrm{g} / \mathrm{ml}$, or rhodamine-conjugated goat anti-mouse IgG (Boehringer-Mannheim) at $1: 100$. The heads were washed four times over $60 \mathrm{~min}$ and incubated with strepavidin-horseradish peroxidase conjugate (BRL) at $1: 150$ for $1 \mathrm{hr}$. (The specific activity of this last reagent is critical to the sensitivity and clarity of the hairy signal and diminishes significantly over several months of storage at $4^{\circ} \mathrm{C}$.) The heads were washed again with four changes of buffer over $60 \mathrm{~min}$ and then rinsed twice with $0.1 \mathrm{M}$ Tris $-\mathrm{HCl}$ (pH 6.8). The peroxidase signal was then developed in $0.1 \mathrm{M}$ Tris $-\mathrm{HCl}$ $(\mathrm{pH} 6.8), 0.5 \mathrm{mg} / \mathrm{ml}$ diaminobenzidine (DAB), containing $0.03 \%$ $\mathrm{Co}^{2+}$ and $\mathrm{Ni}^{2+}$, and $0.02 \% \mathrm{H}_{2} \mathrm{O}_{2}$. If 4,6-diamidino-2-phenyl-indole (DAPI) counterstaining (Carroll et al. 1988) was desired, then heads were returned to wash buffer and incubated for 15 min with $1 \mu \mathrm{g} / \mathrm{ml}$ DAPI before being placed in the mounting solutions.
For mounting, the tissues were rinsed twice with $50 \mathrm{~mm}$ Tris- $\mathrm{HCl}(\mathrm{pH} 8.8)$ and placed in $50 \mathrm{~mm}$ Tris- $\mathrm{HCl}(\mathrm{pH} 8.8)$, containing $10 \%$ glycerol (vol/vol) overnight. Imaginal tissues were dissected from the heads and mounted on polylysine-coated slides. Bright-field photography was normally done with Kodak Technical Pan film (ASA 50), and fluorescence photography was done with Kodak Tri-X film (ASA 400). Where images of DAPI, rhodamine, and DAB triply labeled tissues were desired, we used the faster Tri-X film to record the bright-field pictures as well.

\section{Acknowledgments}

We thank Randy Bennett, Mike Hoffman, Danny Brower, Jim Posakony, Lewis Held, Nick Baker, and Gerry Rubin for technical pointers, patient explanations of disc development, and consultations on data interpretation. We also thank Randy Bennett and Mike Hoffman for a sample of the $22 \mathrm{C} 10$ monoclonal antibody (originally from Seymour Benzer), and Nipam Patel for a gift of monoclonal anti-en antibody. We thank Allen Laughon for his continued interest in all phases of this work and for his review of the manuscript, Bruce Thalley and Mike Hoffman for their comments on the paper, and Pat Hanson for putting it all together. This work was supported by National Science Foundation (NSF) grant DCB-8801814 and an NSF Presidential Young Investigator Award (DCB-8857124) to S.B.C.

\section{References}

Akam, M.E. 1987. The molecular basis for metameric pattern in the Drosophila embryo. Developmental 101: 1-22.

Akam, M.E. and A. Martinez-Arias. 1985. The distribution of Ultrabithorax transcripts in Drosophila embryos. EMBO I. 4: $1689-1700$.

Anderson, K.V. and C. Nüsslein-Volhard. 1986. Dorsal-group genes of Drosophila. Symp. Soc. Dev. Biol. 44: 177-194.

Banerjee, V., P.I. Renfranz, D.R. Hinton, B.A. Rabin, and S. Benzer. 1987. The sevenless protein is expressed apically in cell membranes of the developing Drosophila retina; It is not restricted to cell R7. Cell 51: 151-158.

Bienz, M., G. Saari, G. Tremml, J. Muller, B. Zust, and P.A. Lawrence. 1988. Differential regulation of the Ultrabithorax expression in two germ layers of Drosophila. Cell 53: 567 576.

Botas, J., J. Moscoso del Prado, and A. Garcia-Bellido. 1982. Gene dose titration analysis in the search of trans-regulatory genes in Drosophila. EMBO J. 1: 307-310.

Boulet, A.M. and M.P. Scott. 1988. Control elements of the P2 promoter of the Antennapedia gene. Genes Dev. 2: 16001614.

Brower, D.L. 1987. Ultrabithorax gene expression in Drosophila imaginal disc and larval nervous system. Development 101: 83-92.

Bryant, P.J. 1975. Pattern formation in the imaginal wing disc of Drosophila malanogaster: Fate map, regeneration and duplication. I. Exp. Zool. 193: 49-78.

1978. Pattern formation in imaginal discs. In Genetics and biology of Drosophila led. M. Ashburner and T.R.F. Wright), vol. 2c, pp. 229-335. Academic Press, New York.

Campos-Ortega, J.A. and A. Hofbauer. 1977. Cell clones and pattern formation: On the lineage of photoreceptor cells in the compound eye of Drosophila. Wilhelm Roux's Arch. 181: $227-245$.

Carroll, S.B. and M.P. Scott. 1985. Localization of the fushi tarazu gene product during Drosophila embryogenesis. Cell 43: 47-57. 
Carroll, S.B. and M.P. Scott. 1986. Zygotically active genes that affect the spatial expression of the fushi tarazu segmentation gene during early Drosophila embryogenesis. Cell 45: $113-126$

Carroll, S.B., R.A. Laymon, M.A. McCutcheon, P.D. Riley, and M.P. Scott. 1986. The localization and regulation of Antennapedia protein expression in Drosophila embryos. Cell 47: $113-122$.

Carroll, S.B., A. Laughon, and B.S. Thalley. 1988. Expression, function and regulation of the hairy segmentation protein in the Drosophila embryo. Genes Dev. 2: 883-890.

DiNardo, S., J.M. Kuner, J. Theis, and P.H. O'Farrell. 1985. Development of embryonic pattern in $\mathrm{D}$. melanogaster as revealed by accumulation of the nuclear engrailed protein. Cell 43: 59-69.

Doe, C.Q., D. Smouse, and C.S. Goodman. 1988a. Control of neuronal fate by the Drosophila segmentation gene evenskipped. Nature 333: 376-378.

Doe, C.Q., Y. Hiromi, W.J. Gehring, and C.S. Goodman. 1988b. Expression and function of the segmentation gene fushi tarazu during Drosophila neurogenesis. Science 239: 170175.

Fain, M.J. and B. Stevens. 1982. Alterations in the cell cycle of Drosophila imaginal disc cells precede metamorphosis. Dev. Biol. 92: 247-258.

Frasch, M. and M. Levine. 1987. Complementary patterns of even-skipped and fushi tarazu expression involve their differential regulation by a common set of segmentation genes in Drosophila. Genes Dev. 1: 981-995.

Frasch, M., T. Hoey, C. Rushlow, H. Doyle, and M. Levine. 1987. Characterization and localization of the even-skipped protein of Drosophila. EMBO I. 6: 749-760.

Fristrom, D. 1976. The mechanism of evagination of imaginal discs of Drosophila melanogaster. III. Evidence for cell rearrangement. Dev. Biol. 54: 163-171.

Fristrom, D. and J.W. Fristrom. 1975. The mechanism of evagination of imaginal discs of Drosophila melanogaster. I. General considerations. Dev. Biol. 43: 1-23.

Fujita, S.C., S.L. Zipursky, S. Benzer, A. Ferrus, and S.L. Shotwell. 1982. Monoclonal antibodies against the Drosophila nervous system. Proc. Natl. Acad. Sci. 79: 7929-7933.

Garcia-Bellido, A. and J.R. Merriam. 1971. Genetic analysis of cell heredity in imaginal discs of Drosophila melanogaster. Proc. Natl. Acad. Sci. 65: 2222-2228.

Ghysen, A. and C. Dambly-Chaudiere. 1988. From DNA to form: The achaete-scute complex. Genes Dev. 2: 495-501.

Graves, B.J. and G. Schubiger. 1982. Cell cycle changes during growth and differentiation of imaginal leg discs in Drosophila melanogaster. Dev. Biol. 93: 104-110.

Held, L.I., Jr., and P.J. Bryant. 1984. Cell interactions controlling the formation of bristle patterns in Drosophila. In Pattern formation: A primer in developmental biology (ed. G.M. Malacinski and S.V. Bryant), pp. 291-322. Macmillan, New York and London.

Hiromi, Y., A. Kuroiwa, and W.J. Gehring. 1985. Control elements of the Drosophila segmentation gene fushi tarazu. Cell 43: 603-613.

Holmgren, R. 1984. Cloning sequences from the hairy gene of Drosophila. EMBO I. 3: 569-573.

Howard, K. and P. Ingham. 1986. Regulatory interactions between the segmentation genes fushi tarazu, hairy, and engrailed in the Drosophila blastoderm. Cell 44: 949-957.

Howard, K., P. Ingham, and C. Rushlow. 1988. Region-specific alleles of the Drosophila segmentation gene hairy. Genes Dev. 2: 1037-1046.

Ingham, P.W. and J.P. Gergen. 1988. Interactions between the pair-rule genes runt, hairy, even-skipped, and fushi tarazu and the establishment of periodic pattern in the Drosophila embryo. Dev. Suppl. 104: 51-60.

Ingham, P., S.M. Pinchin, K.R. Howard, and D. Ish-Horowicz. 1985. Genetic analysis of the hairy gene in Drosophila. Genetics 111: 463-486.

Ish-Horowicz, D. and S.M. Pinchin. 1987. Pattern abnormalities induced by ectopic expression of the Drosophila give hairy are associated with repression of $\mathrm{ftz}$ transcription. Cell 51: 405-415.

Ish-Horowicz, D., K.R. Howard, S.M. Pinchin, and P.W. Ingham. 1985. Molecular and genetic analysis of the hairy locus in Drosophila. Cold Sprint Harbor Symp. Quant. Biol. 50: $135-144$.

Kornberg, T., I. Siden, P. O'Farrell, and M. Simon. 1985. The engrailed locus of Drosophila: in situ localization of transcripts reveals compartment-specific expression. Cell 40: $45-53$

Lehmann, R., F. Jimenez, U. Dietrich, and J.A. Campos-Ortega. 1983. On the phenotype and development of mutants of early neurogenesis in Drosophila melanogaster. Wilhelm Roux's Arch. Dev. Biol. 192: 62-74.

Lewis, E.B. 1978. A gene complex controlling segmentation in Drosophila. Nature 276: 565-570.

Murray, M.A., M. Schibiger, and J. Palka. 1984. Neuron differentiation and axon growth in the developing wing of Drosophila melanogaster. Dev. Biol. 104: 259-273.

Nüsslein-Volhard, C., H.G. Frohnhöfer, and R. Lehmann. 1987. Determination of anteroposterior polarity in the Drosophila embryo. Science 238: 1675-1681.

Peifer, M., F. Karch, and W. Bender. 1987. The bithorax complex: Control of segmental identity. Genes Dev. 1: 891-898.

Ready, D.F., T.E. Hanson, and S. Benzer. 1976. Development of the Drosophila retina, a neurocrystalline lattice. Dev. Biol. 53: $217-240$.

Schubiger, M. and J. Palka. 1987. Changing spatial patterns of DNA replication in the developing wing of Drosophila. Dev. Biol. 123: $145-153$.

Scott, M.P. and S.B. Carroll. 1987. The segmentation and homeotic gene network in early Drosophila development. Cell 51: $689-698$.

Simpson, P. and G. Morata. 1980. The control of growth in the imaginal discs of Drosophila. In Development and neurobiology of Drosophila (ed. O. Sidding, P. Babu, L.M. Hall, and J.C. Hall), pp. 129-140. Plenum Press, New York and London.

Tomlinson, A. 1985. The cellular dynamics of pattern formation in the eye of Drosophila. I. Embryol. Exp. Morph. 89: $313-331$

- 1988. Cellular interactions in the developing Drosophila eye. Development 104: 183-193.

Tomlinson, A., D.D.L. Bowtell, E. Hafen, and G.M. Rubin. 1987. Localization of the sevenless protein, a putative receptor for positional information in the eye imaginal disc of Drosophila. Cell 51: 143-150.

Zipursky, S.L., T.D. Venkatesh, D.B. Teplow, and S. Benzer. 1984. Neuronal development in the Drosophila retina: Monoclonal antibodies as molecular probes. Cell 36: 15-21. 


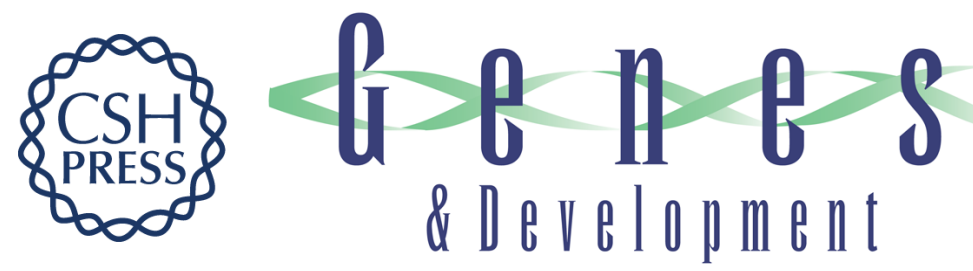

\section{The role of the hairy gene during Drosophila morphogenesis: stripes in imaginal discs}

Genes Dev. 1989, 3:

Access the most recent version at doi:10.1101/gad.3.6.905

References This article cites 47 articles, 11 of which can be accessed free at: http://genesdev.cshlp.org/content/3/6/905.full.html\#ref-list-1

License

Email Alerting Receive free email alerts when new articles cite this article - sign up in the box at the top Service right corner of the article or click here.

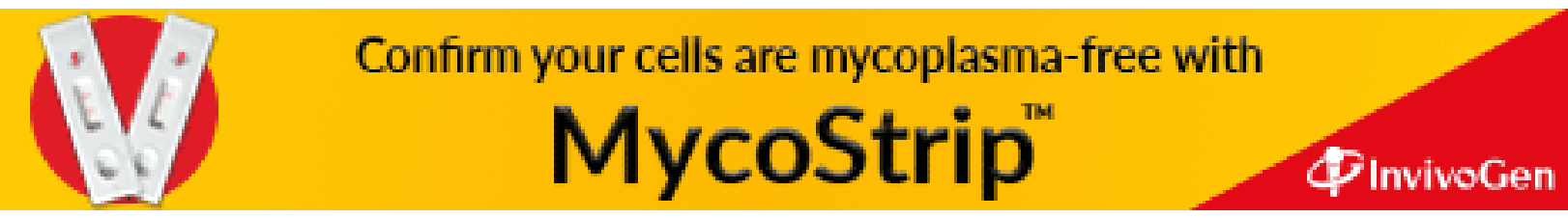

